\title{
ARTICLE
}

\section{Ketamine as a rapid antidepressant: the debate and implications}

\author{
Roger C. M. Ho \& Melvyn W. Zhang
}

Roger Ho is an Associate Professor and consultant psychiatrist in the Department of Psychological Medicine, Yong Loo Lin School of Medicine, National University of Singapore. He has a special interest in psychoneuroimmunology and the interface between medicine and psychiatry. Melvyn Zhang is a senior resident with the National Addiction Management Service, Institute of Mental Health, Singapore.

Correspondence DrRoger C. M. Ho, National University of Singapore, Department of Psychological Medicine, Level 9 NUHS Tower Block, 1E Kent Ridge Road, Singapore, Singapore 119228. Email: roger_ho@nuhs.edu.sg

\begin{abstract}
SUMMARY
Ketamine, a synthetic derivative of phencyclidine, is a commonly misused party drug that is restricted in high-income countries because of its addictive potential. Ketamine is also used as an anaesthetic in human and veterinary medicine. In the 1990s, research using ketamine to study the pathophysiology of schizophrenia was terminated owing to ethical concerns. Recently, controversy surrounding the drug has returned, as researchers have demonstrated that intravenous ketamine infusion has a rapid antidepressant effect and have therefore proposed ketamine as a novel antidepressant. This article debates the question of ketamine as an antidepressant, considering the drug's addictive potential, ethical concerns about prescribing a hallucinogen, the evidence base and motives behind ketamine trials.
\end{abstract}

\section{LEARNING OBJECTIVES}

- Understand the pharmacological properties of ketamine as an anaesthetic, a drug of misuse and a proposed antidepressant

- Review the current evidence for ketamine in treating depressive disorder and recognise potential risks associated with long-term use

- Recognise the arguments for and against the use of ketamine as a novel antidepressant

\section{DECLARATION OF INTEREST}

None

Major depressive disorder (MDD) is a common psychiatric illness that is estimated to affect 120 million people worldwide (Li 2011a). The low heritability of MDD (39\%) suggests that environmental rather than genetic factors are contributing more to variations in its phenotype. In the past 50 years, there have been significant advances in the treatment of MDD, including the development of various antidepressants, such as tricyclic antidepressants (TCAs), selective serotonin reuptake inhibitors (SSRIs) and noradrenergic and specific serotonergic antidepressants (NaSSAs). Psychotherapies such as cognitive-behavioural therapy (CBT) and interpersonal psychotherapy are also evidence-based treatments. Given the low heritability of MDD, it is not surprising that response rates to SSRIs and NaSSAs are around $62 \%$ and 67\% respectively (Papakostas 2008). Environmental factors such as relationship problems, financial difficulties and comorbid substance misuse often lead to poor treatment response, and antidepressants combined with CBT have shown promising results in prevention of mood disorders (Brenner 2010). Although 70$90 \%$ of patients with depression achieve remission, around $10-30 \%$ are refractory to initial treatment but respond to switching or combination of antidepressants, electroconvulsive therapy (ECT) or psychotherapy. Around one-third of patients who are refractory to initial treatment do not respond to other antidepressants and combined treatment (Al-Harbi 2012). Hence, 9-10\% of patients with depression have treatment-resistant depression. Recently, some studies have found that ketamine has rapid antidepressant effects in patients with treatment-resistant depression.

\section{What is ketamine?}

Ketamine was first synthesised in 1962, by Calvin Stevens in a Parke-Davis laboratory. It was considered a safer alternative to the hallucinogen phencyclidine (PCP). Parke-Davis patented ketamine as an anaesthetic in 1966. Ketamine was first used as a battlefield anaesthetic in the Vietnam War. The drug induced a dissociative state that was helpful in treating wounded soldiers by keeping them conscious but cognitively separated from pain (Trujillo 2011). During the 1970s, young people started to use ketamine as a recreational drug. Ketamine is still used in veterinary medicine, and also as a battlefield anaesthetic in low- and middle-income countries.

Ketamine is a non-competitive $N$-methyl-Daspartate (NMDA) receptor antagonist. It exists in two optical isomer forms, $\mathrm{S}(+)$ ketamine and $\mathrm{R}(-)$ ketamine. In human brain, $\mathrm{S}(+)$ ketamine binds to the PCP-binding site of the NMDA receptor with fivefold higher affinity than does $\mathrm{R}(-)$ ketamine. A pharmaceutical company is currently testing a nasal spray formulation of the $\mathrm{S}(+)$ ketamine as a potential antidepressant, although no results have been published. Ketamine is metabolised by hepatic cytochromes CYP 3A4, 2B6 and 2C9 into 
dehydronorketamine and norketamine, which can be detected in urine (Li 2011a). Ketamine has a high first-pass effect (Salvadore 2013) and short half-life ( 3h) (Lo 1975). Although ketamine can be administered via the oral, intranasal and intramuscular routes, the intravenous route is preferred because it allows precise dosing and dose adjustment if side-effects occur (Canadian Agency for Drugs and Technologies in Health 2014).

Ketamine can relieve pain through the mu opioid receptors. Its action on the monoaminergic system is similar to that of amphetamine or cocaine (Schatzberg 2014), and the drug is liable to misuse owing to its dopaminergic, opiate and stimulant effects (Moghaddam 1997; Schatzberg 2014). Other pharmacodynamic mechanisms include prevention of the influx of calcium ions and alteration of limbic system functioning (Bergman 1999). Calcium influx into mitochondria may lead to neurotoxicity in the frontal cortex (Xu 2015). Ketamine is associated with memory impairment (Morgan 2014). By blocking NMDA receptors, ketamine exacerbates the psychotic and cognitive symptoms of schizophrenia (Malhotra 1997).

At low doses, ketamine causes euphoria, sensory distortions, impairments in set-shifting and heightened feelings of empathy (Krystal 1994; Jansen 2001; Dillon 2003). At high doses, it causes dissociative effects, hallucination, intoxication and frightening experiences (Trujillo 2011). Lai et al (2014) have demonstrated that the psychotomimetic effects of ketamine are dose-related and that its antidepressant effects may also be. Ketamine misuse is associated with amnesia, dependence, dissociation, lower urinary tract dysfunction and poor impulse control (Li 2011a). The worldwide incidence of ketamine seizures significantly increased between 2003 and 2006 (Xu 2015).

In this review, we will examine recent evidence regarding the use of ketamine as a rapid antidepressant and its potential for misuse (Yang 2014). In arguing that the evaluation of antidepressant ketamine must go beyond clinical trials, we hope to give psychiatrists and patients a better understanding of the drug, its antidepressant efficacy and side-effects, and the controversies surrounding its use in psychiatry.

\section{Current legal status and prevalence of ketamine misuse}

Ketamine misuse is common worldwide, under street names such as $\mathrm{K}$ and Special $\mathrm{K}$. Recreational users snort ketamine powder or inject liquid ketamine. Table 1 shows the current legal status of ketamine in different countries. In the
UK, ketamine is now a class B drug because the prevalence of ketamine misuse among recreational users increased from 25\% to 40\% between 2002 and 2007 (McCambridge 2007). The British Crime Survey of 2010-2011 reported that there were 125000 recreational users of ketamine in the UK (Smith 2011). In the USA, ketamine is a schedule III drug (Schatzberg 2014), and emergency room visits due to ketamine misuse increased by $2000 \%$ between 1995 and 2002 (Substance Abuse and Mental Health Services Administration 2003). In Hong Kong, ketamine is a schedule I drug. It is the most common drug of misuse and consumed by more than $80 \%$ of drug users (Li 2011a). Ketamine is the second most commonly misused drug in Taiwan (Lua 2003), where the age at onset of ketamine misuse is as young as 15 years (Lee 2012). There is pressure to reschedule ketamine to limit its use in Taiwan (Li 2011a). Ketamine has become the second most common drug of misuse in central rural China (Deng 2012). Ketamine misusers have a false perception that ketamine is relatively safe, and this has made it the preferred drug. Some Asian countries have very strict laws on drugs, imposing harsh punishment. In Malaysia and Singapore, anyone caught with ketamine faces imprisonment or strokes of the cane (Central Narcotics Bureau 2013). Repeat offenders may face the death penalty in Malaysia.

\section{Controversies surrounding ketamine}

The use of ketamine in psychiatric research has been the subject of controversy over recent decades (Table 2).

\section{Ketamine and schizophrenia}

The first debate occurred in 1999 (Marshall 1999), when the National Institute of Mental Health (NIMH) suspended a US study in which ketamine was used to induce psychosis in patients with schizophrenia. Researchers argued that such ketamine challenge studies would

TABLE 1 Restriction of ketamine use in different countries

\begin{tabular}{|c|c|c|c|}
\hline \multicolumn{2}{|c|}{ Restricted by schedule } & \multirow[b]{2}{*}{$\begin{array}{l}\text { Restricted by other } \\
\text { legislation }\end{array}$} & \multirow[b]{2}{*}{$\begin{array}{l}\text { Unrestricted and } \\
\text { legal to use }\end{array}$} \\
\hline $\begin{array}{l}\mathrm{I} / \mathrm{II}, \mathrm{A} / \mathrm{B} \text { or } \mathrm{X} \\
\text { (greatest restriction) }\end{array}$ & $\begin{array}{l}\text { III/IV or C/D } \\
\text { (least restriction) }\end{array}$ & & \\
\hline $\begin{array}{l}\text { Canada (I) } \\
\text { China (I) } \\
\text { Denmark (B) } \\
\text { Hong Kong (I) } \\
\text { India (X) } \\
\text { Singapore (B) } \\
\text { UK (B) }\end{array}$ & $\begin{array}{l}\text { Australia (IV) } \\
\text { Mexico (III) } \\
\text { New Zealand ( C ) } \\
\text { Sweden (IV) } \\
\text { USA (III) }\end{array}$ & $\begin{array}{l}\text { Brazil (veterinary law, not for } \\
\text { human use) } \\
\text { Malaysia (Dangerous Drugs } \\
\text { Act 1952) } \\
\text { Philippines (Comprehensive } \\
\text { Dangerous Drugs Act 2002) }\end{array}$ & $\begin{array}{l}\text { Iran } \\
\text { Netherlands } \\
\text { Romania }\end{array}$ \\
\hline
\end{tabular}




\begin{tabular}{|c|c|c|}
\hline & 1990s: schizophrenia & 2010s: depression \\
\hline Countries & USA & USA, UK, Canada, Ireland \\
\hline $\begin{array}{l}\text { Research purpose of using } \\
\text { ketamine }\end{array}$ & $\begin{array}{l}\text { To induce psychotic symptoms and understand the efficacy of } \\
\text { schizophrenia drugs }\end{array}$ & $\begin{array}{l}\text { To study the rapid antidepressant effect of ketamine in patients with } \\
\text { major depressive disorder, treatment-resistant depression or bipolar } \\
\text { depression }\end{array}$ \\
\hline \multirow[t]{6}{*}{ The concerns } & \multirow{6}{*}{$\begin{array}{l}\text { The study caused harm in psychiatric patients and healthy } \\
\text { volunteers } \\
\text { It is unethical to induce psychosis in psychiatric patients and } \\
\text { healthy volunteers. The argument is that cardiologists would not } \\
\text { induce a heart attack in research participants to understand the } \\
\text { pathophysiology of myocardial infarction; likewise, psychiatrists } \\
\text { should not induce psychosis in research participants to understand } \\
\text { schizophrenia }\end{array}$} & $\begin{array}{l}\text { Ketamine fails to maintain the acute mood elevation, and patients } \\
\text { will crash into depressive states shortly after stopping use }\end{array}$ \\
\hline & & $\begin{array}{l}\text { The acute mood elevation is rewarding and results in addiction when } \\
\text { ketamine is administered repeatedly over time }\end{array}$ \\
\hline & & $\begin{array}{l}\text { The prescription of oral or intranasal ketamine for depression may } \\
\text { lead to widespread diversion }\end{array}$ \\
\hline & & $\begin{array}{l}\text { Most studies were underpowered and lacked active antidepressant } \\
\text { control arms }\end{array}$ \\
\hline & & $\begin{array}{l}\text { Some doctors prescribed ketamine for treatment-resistant } \\
\text { depression, delaying required proven treatments such as ECT } \\
\text { (Kellner 2014) }\end{array}$ \\
\hline & & $\begin{array}{l}\text { Some trials were conducted by researchers and/or bodies that own } \\
\text { patents on using ketamine to treat depression. The financial conflict } \\
\text { of interest will lead to ethical problems if ketamine causes addiction } \\
\text { in treated patients }\end{array}$ \\
\hline \multirow[t]{5}{*}{ The outcomes } & $\begin{array}{l}\text { The US President's National Bioethics Advisory Commission } \\
\text { recommended more protection for psychiatric patients participating }\end{array}$ & $\begin{array}{l}\text { At least } 12 \text { studies were completed and published in peer-reviewed } \\
\text { journals; } 5 \text { of the } 12 \text { were conducted by NIMH researchers }\end{array}$ \\
\hline & in research & \multirow{2}{*}{$\begin{array}{l}\text { Professional bodies such as the American Psychiatric Association } \\
\text { and the Royal College of Psychiatrists have not made any official } \\
\text { statement on this matter }\end{array}$} \\
\hline & $\begin{array}{l}\text { The head of the NIMH said that the study had serious ethical } \\
\text { shortcomings }\end{array}$ & \\
\hline & The study was suspended by the NIMH & \multirow{2}{*}{$\begin{array}{l}\text { The media hold conflicting views of ketamine studies (McKie 2014; } \\
\text { Siddique 2014). Some researchers and media reports were criticised } \\
\text { for overplaying ketamine's antidepressant effect (Zhang MW 2015) }\end{array}$} \\
\hline & The media held negative views of ketamine studies & \\
\hline
\end{tabular}

generate important new knowledge about the pathophysiology of schizophrenia and improve patients' well-being (Carpenter 1999). However, after 15 years, ketamine trials have neither changed the treatment nor improved the outcome of schizophrenia.

\section{Ketamine and depression}

Controversy regarding ketamine has arisen in the current decade. This time, researchers have shifted the focus to depression and propose using ketamine as a rapid antidepressant to treat MDD, treatmentresistant depression or bipolar depression. Their trials try to convince psychiatrists that low-dose ketamine is a rapid antidepressant and does not cause addiction or memory impairment. Some researchers have proposed repeated ketamine infusions to maintain its antidepressant effect. Yet here is the problem. In the past two decades, we have gained more knowledge about the misuse potential of ketamine and its harmful psychological and physical consequences (Morgan 2012). Many governments have rescheduled ketamine to exert tighter control over the drug. Claims that low-dose ketamine is a non-addictive and safe antidepressant are based on just short periods of observation: cross-sectional (Tang 2015) and longitudinal studies (Morgan 2010) have found that regular consumption of ketamine leads to addiction, depression and cognitive impairment. The proposed repeated infusions of ketamine may lead to addiction, just as repeated low-dose intake of other common substances of misuse, such as nicotine, can. There is no evidence to suggest that repeated infusions of ketamine at subanaesthetic doses would not cause addiction.

Recent reviews discuss the potential of ketamine as an antidepressant (Salvadore 2013; DeWilde 2015), but their authors include employees and advisors of the pharmaceutical company that owns the manufacturer of intranasal ketamine. These reviews give minimal coverage to ketamine misuse and potential complications of chronic use. They may underestimate the risks of repeated administration of ketamine to maintain its antidepressant effects (Salvadore 2013).

Some researchers recommend integrating ketamine into in-patient antidepressant treatment (Naughton 2014). By contrast, others emphasise that two-thirds of patients relapsed within 1 week and not all patients with MDD respond to intravenous ketamine (Katalinic 2013). Rasmussen (2016) stresses that the safety of prolonged ketamine use has not been established and that enthusiasm must be tempered by consideration of its addiction potential and tolerance effects. 
The rapid antidepressant effect of ketamine is not unique, and most psychedelic drugs, such as amphetamine and cocaine, demonstrate an acute mood-elevation effect (Fig. 1). Indeed, amphetamine was found to be a powerful antidepressant in the 1930s (Hirschfield 2012). However, this acute mood elevation is short-lived, and recipients will crash into depressive states after stopping use (Barr 2002). The recipient tries to avoid the crash or withdrawal by taking more of the drug. The acute mood elevation is rewarding and leads to addiction.

In addition, recent animal studies have shown how ketamine could successfully reverse the hypodopaminergic state following withdrawal from amphetamine. This finding suggests that ketamine has a stimulant effect (Belujon 2016). This stimulant effect may be responsible for the rapid antidepressant effects that have been reported in most clinical trials conducted on people with depression. As yet, there is no scientific evidence to prove that the rapid antidepressant effect associated with ketamine is different from the 'drug high' of stimulants. Consequently, ketamine is not safe for regular use.

There are other concerns related to ketamine use in the treatment of MDD. Aan het Rot et al (2010) recommend that ketamine should not be administered outside the hospital. Torre (2010) urges that knowledge of cognitive impairment and reduction in well-being associated with frequent ketamine use be disseminated to both clinicians and the general public. Li et al (2011a) highlight the risks of ketamine, including urinary tract dysfunction, risk of diversion of prescribed ketamine and the fact that ketamine may cause more harm than some of the drugs scheduled in the United Nations international drug control conventions. Most reviews end inconclusively, suggesting that more research needs to be done, but none of the reviews attempts to explore other issues, including ethics, conflict of interest and motives behind ketamine research. No evidencebased guidelines recommend intravenous ketamine in the treatment of MDD. However, a report by the Canadian Agency for Drugs and Technologies lists four important conclusions and implications (Box 1), and The Maudsley Guidelines (Taylor 2015) list the pros and cons of ketamine prescription.

\section{The current evidence on ketamine as a novel and rapid antidepressant}

In the past 15 years, at least 12 studies were conducted to assess the efficacy of ketamine as an antidepressant, but most studies were not adequately powered because of small sample size

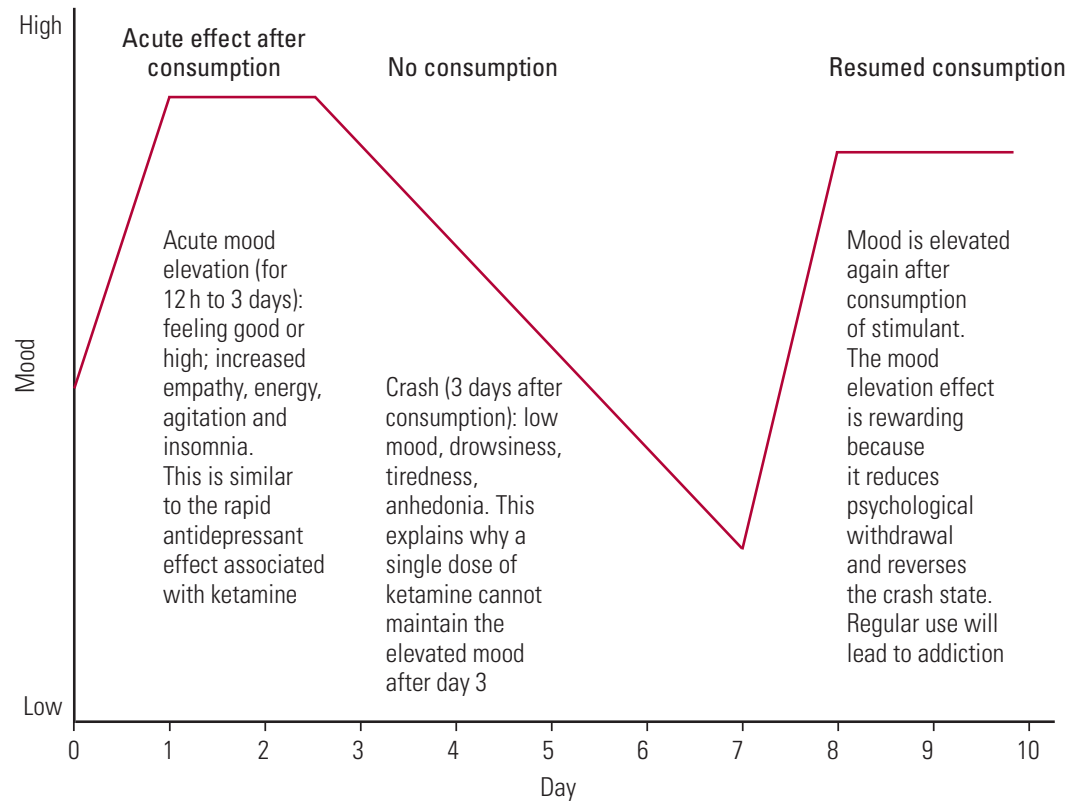

FIG 1 The effect of stimulants (e.g. amphetamine, cocaine) on mood.

(online Table DS1). Seven of the 12 that we identified were by authors and/or an institution that reported a financial conflict of interest regarding the use of antidepressant ketamine; four were published in a single journal, Biological Psychiatry. The response rate ranged from 29\% (Diamond 2014) to $79 \%$ (Zarate 2012). The relapse rate was as high as 73\% (Ibrahim 2012). Not all patients with treatment-resistant depression responded to ketamine. Predictors of poor response included a large hippocampus (Abdallah 2014), homozygous met/met alleles of the brain-derived neutrophic

\section{BOX 1 Recommendations of the Canadian Agency for Drugs and Technologies in Health (2014)}

- Psychiatrists need to be mindful that most ketamine trials did not specify which previous treatments patients had received and that the effect of ketamine was compared with placebo or midazolam, but not with active antidepressants

- The requirement for overnight hospital admission for intravenous ketamine administration makes the logistics of treatment more complicated than with conventional antidepressants

- The evidence claiming that intravenous ketamine can reduce suicidal ideation is of poor quality; there is no evidence that intravenous ketamine can prevent actual suicide attempts

- There is a lack of current evidence to recommend ketamine as a standard treatment for common psychiatric disorders (e.g. major depressive disorder, post-traumatic stress disorder) 
factor $(B D N F)$ gene (Liu 2011), lack of initial mood elevation effect (Murrough 2013a) and old age (age-related brain changes affect sensitivity to ketamine) (Szymkowicz 2014).

Owing to low remission rates and the short half-life of ketamine, researchers have advocated multiple ketamine infusions to maintain its antidepressant effect (aan het Rot 2010; Diamond 2014). Oral and intranasal ketamine were proposed for convenient administration. This practice is similar to chronic ketamine use by recreational users. Long-term ketamine use activates glutamate neurotransmission in the prefrontal cortex and leads to neurotoxicity (Krystal 1994).

The researchers emphasise the safety of a subanaesthetic dose of ketamine and distinguish its effects from thehigh doses used by recreational users. The administration of subanaesthetic doses is not without risk, and a single subanaesthetic ketamine infusion causes side-effects in $2 \%$ of participants (Salvadore 2013). The pharmacodynamics of subanaesthetic doses of ketamine that lead to its euphoric effect is a topic of research. In animal studies, subanaesthetic doses were associated with acute increases in extracellular glutamate and dopamine in the prefrontal cortex (Moghaddam 1997) and anterior cingulate cortex (Stone 2012), leading to excitatory neurotransmission. Other mechanisms of action include activation of amino methyl isoxazole propionic acid (AMPA) and motor-evoked potentials (Di Lazzaro 2003).

\section{Critical appraisal of current trial evidence}

The studies in question (Table DS1) have a number of flaws that caution against the widespread use of ketamine.

First, selection bias occurred in the Ghasemi et al (2014) trial, as patients randomised to the ketamine group had lower mean depression scores than those randomised to the ECT group (30.22 v. $35.88, P=0.07$, which is approaching statistical significance). Second, in all of the studies, the follow-up period was too short to rule out addiction and complications associated with regular ketamine infusion. Third, ketamine was used with other psychotropic medications in some studies (DiazGranados 2010b; Zarate 2012; Diamond 2014; Lapidus 2014). Researchers were not able to distinguish whether the antidepressant effect was due to other medications or the sole effect of ketamine. Fourth, in one study (Mathew 2010) the depression rating scale used as the indicator of response was administered twice within 3 days. This could lead to bias, because participants might remember their previous responses and give better ones, especially in an open-label trial. Fifth, DiazGranados et al (2010a) reported rapid resolution of suicidal ideation after a single infusion of ketamine. This study used the Beck Scale for Suicidal Ideation (SSI), on which higher scores indicate higher suicidal ideation. Participants were separated into two groups on the basis of scores (range 0-10) derived from analysis of their total SSI scores: those with significant suicidal ideation (scores $>3$ ) and those without significant suicidal ideation (scores $<4$ ). DiazGranados et al note that this cutoff threshold of $3 / 4$ has been used before to indicate clinically significant suicidal ideation. However, the study to which they refer (Holi 2005) was in an adolescent population. In adult populations some studies (e.g. Sokero 2003) have used a cut-off of $>6$. Thus, the suicidal ideation scores were relatively low to begin with. There was a small reduction in the magnitude of suicidal ideation, but the results might not be clinically significant. Sixth, the studies were not able to ascertain the differences between the rapid antidepressant effect of ketamine and the 'drug high' of recreational drugs. Mathew et al (2010) proposed head-to-head comparison of intravenous ketamine and intravenous amphetamine, but such a study might not be ethical. Seventh, having a placebo arm is crucial in antidepressant trials, because placebo achieves a response rate between $30 \%$ and $40 \%$ in people with MDD (Sonawalla 2002). As a result, the results of the openlabel studies (Mathew 2010; Murrough 2013a; Diamond 2014) are less reliable. Eighth, although some of the randomised controlled trials (RCTs) were claimed to be double-blind, the effects of ketamine (e.g. dissociation) would be obvious even to masked ('blinded') assessors. This might lead to bias in assessment, because the assessors would know which participants were randomised to the ketamine group. Such bias might affect the accuracy of findings. Last, none of the 12 trials was conducted in Asia, Africa or South America, and this limits the generalisation of findings to non-Western populations. Meta-analyses of the studies demonstrate significant acute mood elevation shortly after ketamine infusion (Coyle 2015; Lee 2015). This is not surprising, because all of the trials showed positive results, and Lee et al's (2015) meta-analysis did not perform Egger's regression test or show $P$-values when calculating the publication bias.

\section{Further debate}

Some researchers assume that ketamine is a rapid antidepressant because depressive symptoms were lifted immediately after infusion. Following the same logic, if other psychedelic drugs of misuse, 
such as amphetamine or 3,4-methylenedioxymethamphetamine (MDMA), lift depression immediately, these drugs are also potential 'rapid antidepressants'. Researchers are selectively focusing on the artificial mood elevation of ketamine, forgetting the long-term risk associated with its misuse and the fact that depression is a chronic illness. If ketamine causes addiction in patients with depression, the dual diagnosis will increase the healthcare burden. More points in the debate are outlined in Table 3.

\section{Potential risk of repeated ketamine infusions}

\section{Exacerbated depression}

As ketamine is usually used as an anaesthetic for single administration, the risks of repeated administration are unknown (Salvadore 2013). Psychiatrists need to be mindful that acute and chronic administration of ketamine have different effects on the brain. Acute ketamine use increases (Moghaddam 1997) whereas chronic ketamine use decreases (Narendran 2005) brain dopamine levels (Tang 2015). If ketamine is an effective antidepressant for chronic use, why did Morgan et al (2010) record increasing depression scores (i.e. increasing depressive symptoms) among frequent ketamine misusers over a 12-month period? Moreover, patients who demonstrate poor initial response will not respond to further ketamine infusions (Murrough 2013a). Thus, the rapid antidepressant effect after a single ketamine infusion does not imply that regular ketamine infusion will have a long-term antidepressant effect, let alone that it is safe for long-term use.

\section{Risk of dependence}

Researchers have claimed that ketamine does not cause dependence (Diamond 2014), but this contradicts current evidence. There is biochemical and behavioural evidence to suggest that ketamine indeed causes dependence with chronic use, even at subanaesthetic doses. Anticholinergic or amphetamine-like antidepressant medications are misused by patients (Nunes 1996). A subanaesthetic dose of ketamine is associated with psychomotor activation, which, applying the psychomotor stimulant theory of drug reward (Wise 1988), increases the addictive potential of the drug (Trujillo 2011). Animal studies show that acute ketamine infusion produces immediate mood elevation by increasing dopamine levels in the prefrontal cortex (Tan 2012). This reward effect enhances animals' self-administration of ketamine (Carroll 1983; De Luca 2011).
TABLE 3 Assumptions held by ketamine researchers and counterarguments

\begin{tabular}{|c|c|}
\hline Assumption & Counterarguments \\
\hline \multirow[t]{2}{*}{$\begin{array}{l}\text { Current antidepressants are associated with } \\
\text { poor response and lack clinical effectiveness } \\
\text { (Murrough 2012; Thakurta 2012; Hasselmann } \\
\text { 2014) }\end{array}$} & $\begin{array}{l}\text { This assumption is based on overestimates } \\
\text { of the prevalence of treatment-resistant } \\
\text { depression (Quevedo 2009) and under- } \\
\text { estimates of the effectiveness of current } \\
\text { treatment: 9-10\% of patients with depression } \\
\text { are genuinely treatment resistant }\end{array}$ \\
\hline & $\begin{array}{l}\text { Sackeim et al (2001) highlighted that a large } \\
\text { number of patients are undertreated, resulting } \\
\text { in pseudo-resistance to treatment }\end{array}$ \\
\hline \multirow{3}{*}{$\begin{array}{l}\text { Conventional antidepressants have a 3- to } \\
\text { 6-week delay in onset of action (Zarate } \\
\text { 2006; Trujillo 2011; Ibrahim 2012) and have } \\
\text { undesirable side-effects (Quevedo 2009) }\end{array}$} & $\begin{array}{l}\text { Meta-analysis of more than } 50 \text { antidepressant } \\
\text { trials found that antidepressants are }\end{array}$ \\
\hline & $\begin{array}{l}\text { associated with improvement in depressive } \\
\text { symptoms by the end of the first week of use } \\
\text { (Taylor 2006) }\end{array}$ \\
\hline & $\begin{array}{l}\text { There is no evidence to support the claim } \\
\text { that ketamine has a more desirable side- } \\
\text { effect profile compared with conventional } \\
\text { antidepressants }\end{array}$ \\
\hline $\begin{array}{l}\text { Biological intervention is the main treatment } \\
\text { for treatment-resistant depression }\end{array}$ & $\begin{array}{l}\text { Treatment for treatment-resistant depression } \\
\text { should integrate biological and psychological } \\
\text { therapies }\end{array}$ \\
\hline \multirow[t]{2}{*}{ Glutamate has a key role in depression } & $\begin{array}{l}\text { The rapid antidepressant effect of ketamine } \\
\text { cannot prove the role of glutamate in } \\
\text { depression; ketamine does not produce } \\
\text { a hypoglutaminergic state, but leads to } \\
\text { glutamate hyperactivity (Trujillo 2011) }\end{array}$ \\
\hline & $\begin{array}{l}\text { Glutamate is neurotoxic and causes apoptosis } \\
\text { in neurons }\end{array}$ \\
\hline \multirow[t]{2}{*}{$\begin{array}{l}\text { The antidepressant effect of ketamine is } \\
\text { different from ketamine-induced euphoria or } \\
\text { high mood associated with psychedelic drugs } \\
\text { (Berman 2000) }\end{array}$} & $\begin{array}{l}\text { There is no clinical or scientific method to } \\
\text { confirm that the reduction of depressive } \\
\text { symptoms is not due to ketamine-induced } \\
\text { euphoria }\end{array}$ \\
\hline & $\begin{array}{l}\text { Intravenous ketamine infusion is known to } \\
\text { cause euphoria, even at subanaesthetic dose } \\
\text { (Krystal 1994) }\end{array}$ \\
\hline
\end{tabular}

Sanacora \& Schatzberg (2015) have expressed concerns about the misuse potential of ketamine as an antidepressant owing to its effect on the mu opioid receptor. Xu \& Lipsky (2015) believe that the effects of ketamine withdrawal are underestimated because there is no objective scale to assess withdrawal from the drug. In one study, more than half of ketamine misusers reported withdrawal symptoms, including exacerbation of depression, irritability, aggression and fatigue (Chen 2005).

Ketamine is not suitable for oral administration because of its high first-pass rate (Salvadore 2013) and poor bioavailability (Sinner 2008). After oral ingestion, the ketamine's nitroso derivative, $\mathrm{N}$-nitrosoketamine, causes genotoxic effects in cell culture (Toyama 2006). Oral - and intranasal $\mathrm{S}(+)$ ketamine is reinforcing and addictive (Shram 2011) and makes the 'slippery ketamine slope' (Schatzberg 2014) more slippery. Ketamine should be administered in tightly regulated hospital-based treatment under direct observation. 

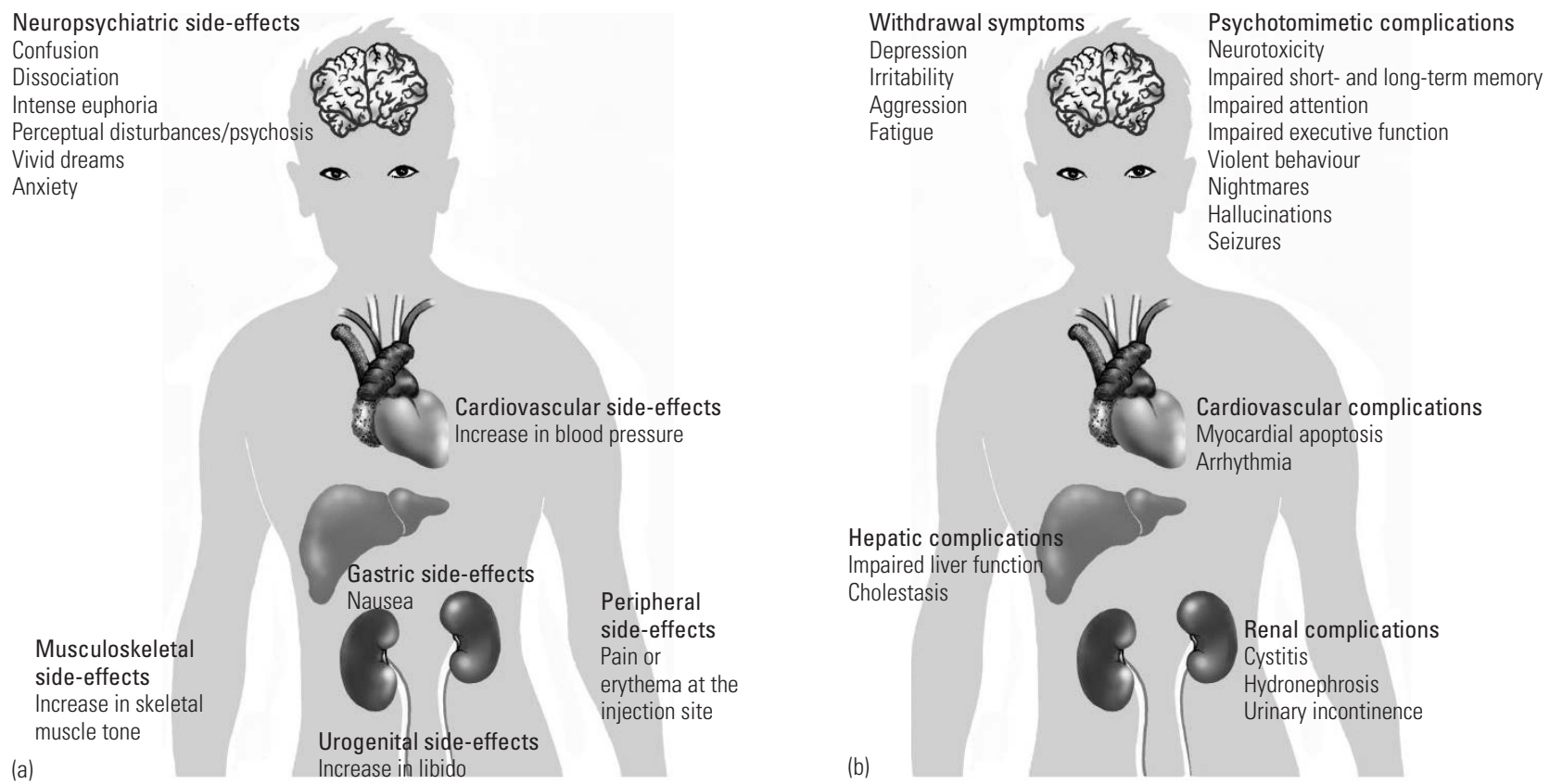

(a) Systemic side-effects of ketamine at subanaesthetic dose (Salvadore 2013); (b) systemic complications of chronic ketamine use (Noppers 2011; Pappachan 2014; Stahl 2014).

\section{Systemic complications}

The proponents of long-term ketamine treatment should be mindful of complications experienced by chronic users (Fig. 2). Their argument that low doses of ketamine would not lead to cognitive impairment is not supported by the evidence. In fact, frequent ketamine users demonstrate impairments in working memory and executive function (Morgan 2010). The claims based on some shortterm trials that ketamine does not cause cognitive impairment are premature, because impairments will become evident only after repeated infusions over the long term. Chronic ketamine use causes pathological changes, including reduction in grey matter in the bilateral frontal cortex that resembles the pattern in schizophrenia (Liao 2011) and epithelial inflammation in the urinary tract that resembles chronic interstitial cystitis. Furthermore, animal studies have demonstrated neurotoxicity after repeated administration of ketamine (Olney 1991).

\section{Challenges to the glutamate theory}

Some researchers suggest that ketamine is a potential antidepressant owing to its antagonism of NMDA receptors (Hasselmann 2014). There is evidence that challenges this postulation. First, ketamine demonstrates a modest affinity for the NMDA receptor over other receptors, implying that the acute mood elevation effect is due to other mechanisms of action (Hillhouse 2014; Sanacora
2015). These mechanisms might include its effect on mammalian target of rapamycin (mTOR) receptors (Li 2011b), BDNF (Autry 2011), the dopamine system (Tan 2012), sigma receptors (Robson 2012) and nicotinic acetylcholine receptors (Nishitani 2014).

Second, if ketamine is an effective antidepressant, we would expect other NMDA receptor antagonists to exhibit antidepressant effects. This is not the case. Memantine is a non-competitive NMDA receptor antagonist, but it does not have a rapid antidepressant effect (Monteggia 2015). Riluzole exerts multiple actions on the ionotropic glutamate receptor system and inhibits NMDA receptors (Debono 1993). In trials, combined riluzole and ketamine treatment did not prevent relapse of depression (Mathew 2010) or alter the course of antidepressant response to ketamine (Ibrahim 2012). Ketamine's primary site of action is the PCP site of the NMDA receptor (Mathew 2010). NMDA antagonists do not have a rapid antidepressant effect, because these drugs do not act on the PCP site. Other researchers suggest that the acute mood elevation effect of ketamine occurs principally through AMPA receptor activation (Sanacora 2008).

\section{Ethical concerns}

Ethical questions relating to the use of ketamine to treat depression have not been fully addressed. Sisti et al (2014) expressed concerns about the 
mental capacity of severely depressed patients when consenting to ketamine treatment. If ketamine is approved by a health authority such as the Medicines Healthcare products Regulatory Agency (MHRA) or the Food and Drug Administration (FDA) as a licensed antidepressant, psychiatrists will feel pressurised to prescribe, especially by patients who are addicted to ketamine. The issues of beneficence and non-maleficence must be considered. Off-label use of ketamine is not without harm. Kellner et al (2014) reported that private anaesthesiologists started to use ketamine to treat depression, but with minimal antidepressant benefits. The authors were worried that such use of ketamine in severely ill people delays commencement of evidence-based treatments such as antidepressants or ECT. Sisti et al (2014) reported that some clinics in the USA offer financial incentives to promote repeated ketamine infusion.

Authors' declarations also reveal potential financial conflicts of interest in the research. The Icahn School of Medicine at Mount Sinai and some of its research employees own the patent for use of intranasal ketamine for the treatment of depression (US 8785500 B2), and they will receive financial benefits if the FDA approves the formulation. Teams at Icahn have conducted various studies demonstrating the positive effects of ketamine in treatment of depression (Berman 2000; Mathew 2010; Murrough 2013a,b; Lapidus 2014). A principal investigator at NIMH is listed as co-inventor of another patent application for the use of ketamine in depression (WO 2013056229 A1), although he has assigned his rights on the patent to the US government (noted in Zarate 2012). It is undeniable that ketamine has significantly reduced research costs in new drug development because it is readily available. The medical profession needs to consider the ethical implications if researchers and institutions will benefit financially by using a psychedelic drug that has misuse potential to treat vulnerable patients. It is crucial to have more clinical trials conducted by independent researchers who have no financial conflicts of interest related to ketamine. This will allow more objective and accurate evaluation of ketamine as a rapid antidepressant.

\section{Safety monitoring during ketamine research}

Not all psychiatric departments and hospitals have issued guidelines for researchers on conducting safe and ethical research into the use of ketamine to treat patients with depression. Table 4 summarises a safety framework that we have compiled from the literature.
TABLE 4 Safety framework for conducting ketamine research in people with depression

\begin{tabular}{|c|c|}
\hline Parameter & Recommendations \\
\hline Age of participants & $\begin{array}{l}\text { Recommended age range: } 18-60 \text { years. Not recommend for children, } \\
\text { adolescents or elderly people (Szymkowicz 2014) }\end{array}$ \\
\hline \multirow[t]{2}{*}{ Severity of depression } & $\begin{array}{l}\text { Participants should be in a severe depressive episode or have } \\
\text { treatment-resistant depression, and should have the capacity to } \\
\text { provide consent }\end{array}$ \\
\hline & $\begin{array}{l}\text { People with adjustment disorder and/or a mild-to-moderate } \\
\text { depressive episode should not be recruited }\end{array}$ \\
\hline \multirow[t]{2}{*}{ Contraindications } & $\begin{array}{l}\text { Psychiatric contraindications: antidepressant-naivity, first-episode } \\
\text { depression, psychosis, schizophrenia, schizoaffective disorder, } \\
\text { unresolved psychosocial problems, grief, past or comorbid substance } \\
\text { misuse }\end{array}$ \\
\hline & $\begin{array}{l}\text { Physical contraindications: pregnancy, breastfeeding, myocardial } \\
\text { infarction, congestive heart failure, low ejection fraction, uncontrolled } \\
\text { hypertension, tachycardia, ventricular arrhythmia, hyperthyroidism }\end{array}$ \\
\hline \multirow[t]{2}{*}{$\begin{array}{l}\text { Previous trial of } \\
\text { antidepressants }\end{array}$} & $\begin{array}{l}\text { Participants should have tried two antidepressants from different } \\
\text { classes at adequate dosage and duration before recruitment into a } \\
\text { ketamine trial }\end{array}$ \\
\hline & $\begin{array}{l}\text { There should be a 2-week wash-out period, especially for monoamine } \\
\text { oxidase inhibitors (MAOls), to avoid serotonin syndrome }\end{array}$ \\
\hline Treatment setting & $\begin{array}{l}\text { Intravenous ketamine infusion should only be used in a clinical setting } \\
\text { with adequate safety monitoring }\end{array}$ \\
\hline Pre-ketamine assessment & $\begin{array}{l}\text { All patients should have physical examination, laboratory } \\
\text { investigations (full blood count, liver function tests, renal function } \\
\text { tests, thyroid function tests, urine toxicology measurements) and } \\
\text { electrocardiogram (ECG) to detect underlying medical illnesses before } \\
\text { ketamine infusion (Fond 2014) }\end{array}$ \\
\hline $\begin{array}{l}\text { Administration of } \\
\text { intravenous ketamine }\end{array}$ & $\begin{array}{l}\text { If intravenous ketamine is given, infusion should be administered } \\
\text { at subanaesthetic dose }(<0.5 \mathrm{mg} / \mathrm{kg} \text { ) over } 40 \mathrm{~min} \text {. Rapid infusion of } \\
\text { ketamine leads to poor tolerability (Lai 2014) }\end{array}$ \\
\hline Involving an anaesthetist & $\begin{array}{l}\text { An anaesthetist should perform an assessment of suitability before } \\
\text { intravenous ketamine infusion. The infusion should be performed } \\
\text { by the anaesthetist with telemetry monitoring. Monitoring } \\
\text { should continue for at least } 1 \mathrm{~h} \text { after infusion. The presence of an } \\
\text { anaesthetist is essential because psychiatrists may not have the } \\
\text { expertise and equipment to perform cardiorespiratory monitoring }\end{array}$ \\
\hline Consent & $\begin{array}{l}\text { Consent should state that: } \\
\text { ketamine is an investigational drug and not officially approved by } \\
\text { the local health authority as a recognised antidepressant treatment; } \\
\text { patients should try conventional antidepressants and/or } \\
\text { psychotherapy before ketamine; } \\
\text { ketamine has possible side-effects (these should be listed); } \\
\text { long-term ketamine treatment may lead to dependence, and } \\
\text { treatment should not be repeated within } 6 \text { months }\end{array}$ \\
\hline $\begin{array}{l}\text { Immediate discontinuation } \\
\text { of intravenous infusion } \\
\text { (Murrough 2013a) }\end{array}$ & $\begin{array}{l}\text { Intravenous ketamine infusion should be discontinued immediately if } \\
\text { any of the following occurs: } \\
\text { systolic blood pressure increase to }>180 \mathrm{mmHg} \\
\text { diastolic blood pressure increase to }>100 \mathrm{mmHg} \\
\text { blood pressure increase to }>20 \% \text { above pre-infusion reading } \\
\text { heart rate increase to }>110 \text { beats per minute }\end{array}$ \\
\hline
\end{tabular}

\section{Research implications of ketamine}

The past 50 years have seen significant advances in psychopharmacology that have reduced the suffering of people with mental illnesses. However, in our opinion the field has now reached a steady state and improvements brought about by new antidepressants are expected to be less dramatic than those achieved 50 years ago. The sudden revisiting of an old drug with misuse 
potential and claims of therapeutic triumph in depression, a condition closely linked with psychosocial aetiologies, require further thought. Treatment-resistant depression is a chronic and complex clinical problem associated with multiple risk factors and to be targeted by integrated therapeutic strategies combining antidepressants with psychosocial interventions. Owing largely to underpowered RCTs and lack of comparison with other antidepressants or stimulants, the evidence base for the therapeutic benefits of ketamine is controversial and not particularly encouraging with regard to maintenance of antidepressant effect. However, the research discussed here has focused on $\mathrm{S}(+)$ ketamine, and researchers have started to investigate the antidepressant properties of $\mathrm{R}(-)$ ketamine. Recent animal studies have demonstrated that the $\mathrm{R}(-)$ isomer of ketamine has a sustained antidepressant effect with addictive potential (Zhang JC 2014; Yang 2015). This finding requires replication in human studies.

Researchers from several countries are competing to replicate the rapid antidepressant effects of ketamine by conducting 'me too' studies and presenting their findings as a breakthrough. One of the reasons could be lack of research funding for the development of new psychotropic drugs. This debate will continue. On one hand, the research findings outlined in Table DS1 support the sensible use of ketamine in a controlled medical

BOX 2 Key messages about ketamine use in treating major depressive disorder or treatment-resistant depression

- The current evidence is not sufficient to recommend ketamine as an antidepressant. Oral and intranasal ketamine carry risk of diversion and misuse.

- Ketamine increases presynaptic glutamate, which is known to cause neurotoxicity. The acute mood elevation effect of ketamine does not explain the role of glutamate and NMDA receptors in depression.

- The differentiation between subanaesthetic and recreational doses of ketamine is not supported by evidence. Repeated use of subanaesthetic doses may lead to addiction and neurotoxicity Similarly, there is no scientific method to differentiate acute mood elevation, euphoria, a 'drug high' and an antidepressant effect of ketamine. The acute mood elevation effect of ketamine is a common intrinsic property of psychedelic drugs. setting to treat depression. Some researchers advocate that ketamine, a class B drug in the UK, should not be excluded from further study. On the other hand, medical professionals need to be mindful of the potentially addictive properties of ketamine, resulting in misuse, possible pressure from patients demanding more frequent ketamine infusions and concerns from the public and legislators, especially in communities seriously hit by ketamine misuse. Such controversies will lead to cognitive dissonance and are best resolved by applying current knowledge to develop safer NMDA receptor-modulating antidepressants.

\section{Implications for psychiatrists and professional bodies}

Using the psychedelic properties of a potentially addictive drug to treat psychiatric disorders presents significant ethical questions. Researchers mainly focus on effect sizes in ketamine trials and underestimate the potential harm of ketamine. Severely depressed patients are desperate for dramatic cures, but psychiatrists should not allow desperation to cloud their clinical judgement (Kellner 2014). Psychiatrists should not overuse ketamine for non-treatment-resistant depression and should not overpromise its therapeutic benefits. Psychiatrists must present the risks and admit that much is unknown about ketamine. It would be unethical and dangerous to society if ketamine were to be widely (mis)used under the label of a 'rapid antidepressant'. Psychiatrists need to be mindful of the possibility of triggering another anti-psychiatry backlash. Although an American Psychiatric Association task force has warned of the misuse potential and risk of neurotoxicity with regular administration of ketamine in clinical settings (Newport 2015), most other professional and regulatory bodies, including the Royal College of Psychiatrists, the Commission on Human Medicines and the Medicines and Healthcare products Regulatory Agency, have issued no guidance on this matter. There is an urgent need for policy discussion to monitor the use of psychedelic drugs in the treatment of psychiatric disorders. The conflicting views on ketamine presented by researchers and by the media (McKie 2014; Siddique 2014) are confusing for the public. We urge postgraduate training committees to help trainees to understand the ethical issues behind the use of ketamine as an antidepressant treatment. Trainees need to apply their knowledge and critical appraisal skills to evaluate published studies on the subject.

Box 2 summarises the key messages of this article. 


\section{Conclusions}

The presentation of ketamine as a novel antidepressant is reminiscent of the ketamine-related controversy in schizophrenia research in the 1990s. There are contradictory reports about its risks and benefits, and both sides present supporting evidence. Psychiatrists should consider other matters, including the psychedelic properties and misuse potential of ketamine, the course of MDD and motives behind ketamine trials. The safety profile of prolonged ketamine use at subanaesthetic doses is not established and chronic use should therefore be restricted. We are concerned that both oral and nasal formulations of ketamine are at risk of diversion, and recommend that the drug only be administered in a hospital setting with tight control. In addition to being of proven efficacy, a novel antidepressant treatment needs to be safe, ethical and based on convincing pharmacodynamic mechanisms.

\section{References}

Aan het Rot M, Collins K, Murrough J, et al (2010) Safety and efficacy of repeated-dose intravenous ketamine for treatment-resistant depression. Biological Psychiatry, 7: 139-45.

Al-Harbi KS (2012) Treatment-resistant depression: therapeutic trends, challenges, and future directions. Patient Preference and Adherence, 6: 369-88.

Abdallah CG, Salas R, Jackowski A, et al (2014) Hippocampal volume and the rapid antidepressant effect of ketamine. Journal of Psychopharmacology, 29: 591-5.

Autry AE, Adachi M, Nosyreva E, et al (2011) NMDA receptor blockade at rest triggers rapid behavioural antidepressant responses. Nature, 475 : 91-5.

Barr AM, Markou A, Phillips AG (2002) A 'crash' course on psychostimulant withdrawal as a model of depression. Trends in Pharmacological Science, 23: 475-82.

Belujon P, Jakobowski NL, Dollish HK, et al (2016) Withdrawal from acute amphetamine induces an amygdala-driven attenuation of dopamine neuron activity: reversal by ketamine. Neuropsychopharmacology, 41: 619-27.

Bergman SA (1999) Ketamine: review of its pharmacology and its use in pediatric anesthesia. Anesthesia Progress, 46: 10-20.

Berman RM, Cappiello A, Anand A, et al (2000) Antidepressant effects of ketamine in depressed patients. Biological Psychiatry, 47: 351-4.

Brenner R, Madhusoodanan S, Puttichanda S, et al (2010) Primary prevention in psychiatry: adult populations. Annals of Clinical Psychiatry, 22: $239-48$.

Canadian Agency for Drugs and Technologies in Health (2014) Intravenous Ketamine for the Treatment of Mental Health Disorders: A Review of Clinical Effectiveness and Guidelines. CADTH.

Carpenter WT Jr (1999) The schizophrenia ketamine challenge study debate. Biological Psychiatry, 46: 1081-91.

Carroll ME, Stotz DC (1983) Oral d-amphetamine and ketamine selfadministration by rhesus monkeys: effects of food deprivation. Journal of Pharmacology and Experimental Therapeutics, 227: 28-34.

Central Narcotics Bureau (2013) Drugs and inhalants. CNB (Singapore) (http://www.cnb.gov.sg/drugs/bannedsubstance/ketamine.aspx). Accessed 17 May 2016.

Chen R, Lee AM, Chan R (2005) Report on a Study on the Cognitive Impairment and other Harmful Effects from Ecstasy and Ketamine
Abuse. Narcotics Division, Security Bureau, Government of the Hong Kong Special Administrative Region.

Coyle CM, Laws KR (2015) The use of ketamine as an antidepressant: a systematic review and meta-analysis. Human Psychopharmacology, 30: 152-63.

Debono MW, Le Guern J, Canton T, et al (1993) Inhibition by riluzole of electrophysiological responses mediated by rat kainate and NMDA receptors expressed in Xenopus oocytes. European Journal of Pharmacology, 235: 283-9.

De Luca MT, Badiani A (2011) Ketamine self-administration in the rat: evidence for a critical role of setting. Psychopharmacology, 214: 549-56.

Deng 0, Tang 0, Schottenfield RS, et al (2012) Drug use in rural China: a preliminary investigation in Hunan Province. Addiction, 107: 610-3

DeWilde KE, Levitch CF, Murrough JW, et al (2015) The promise of ketamine for treatment-resistant depression: current evidence and future directions. Annals of the New York Academy of Sciences, 1345: 47-58.

Diamond PR, Farmery AD, Atkinson S, et al (2014) Ketamine infusions for treatment resistant depression: a series of 28 patients treated weekly or twice weekly in an ECT clinic. Journal of Psychopharmacology, 28: 536-44.

DiazGranados N, Ibrahim LA, Brutsche NE, et al (2010a) Rapid resolution of suicidal ideation after a single infusion of an $\mathrm{N}$-methyl-D-aspartate antagonist in patients with treatment-resistant major depressive disorder. Journal of Clinical Psychiatry, 71: 1605-11.

DiazGranados N, Ibrahim L, Brutsche NE, et al (2010b) A randomized add-on trial of an $\mathrm{N}$-methyl-D-aspartate antagonist in treatment-resistant bipolar depression. Archives of General Psychiatry, 67: 793-802.

Di Lazzaro V, Oliviero A, Profice P, et al (2003) Ketamine increases human motor cortex excitability to transcranial magnetic stimulation. Journal of Physiology, 547: 485-96.

Dillon P, Copeland J, Jansen K (2003) Patterns of use and harms associated with non-medical ketamine use. Drug and Alcohol Dependence, 69: 23-8.

Fond G, Loundou A, Rabu C, et al (2014) Ketamine administration in depressive disorders: a systematic review and meta-analysis. Psychopharmacology, 18: 3663-76.

Ghasemi M, Kazemi MH, Yoosefi A, et al (2014) Rapid antidepressant effects of repeated doses of ketamine compared with electroconvulsive therapy in hospitalized patients with major depressive disorder. Psychiatry Research, 215: 355-61.

Hasselmann HW (2014) Ketamine as antidepressant? Current state and future perspectives. Current Neuropharmacology, 12: 57-70.

Hillhouse TM, Porter JH, Negus SS (2014) Dissociable effects of the noncompetitive NMDA receptor antagonists ketamine and MK-801 on intracranial self-stimulation in rats. Psychopharmacology, 13: 2705-16.

Hirschfield RMA (2012) The epidemiology of depression and the evolution of treatment. Journal of Clinical Psychiatry, 73: 5-9.

Holi MM, Pelkonen M, Karlsson L, et al (2005) Psychometric properties and clinical utility of the Scale for Suicidal Ideation (SSI) in adolescents. BMC Psychiatry, 5: 8.

Ibrahim L, Diazgranados N, Franco-Chaves J, et al (2012) Course of improvement in depressive symptoms to a single intravenous infusion of ketamine vs add-on riluzole: results from a 4-week, double-blind, placebo-controlled study. Neuropsychopharmacology, 37: 1526-33.

Jansen KL, Darracot-Cankovic R (2001) The nonmedical use of ketamine, part two: a review of problem use and dependence. Journal of Psychoactive Drugs, 33: 151-8.

Katalinic N, Lai R, Somogyi A, et al (2013) Ketamine as a new treatment for depression: a review of its efficacy and adverse effects. Australian and New Zealand Journal of Psychiatry, 47: 710-27.

Kellner CH, Greenberg RM, Ahle GM, et al (2014) Electroconvulsive therapy is a standard treatment; ketamine is not (yet). American Journal of Psychiatry, 171: 796

Krystal JH, Karper LP, Seibyl JP, et al (1994) Subanesthetic effects of the noncompetitive NMDA antagonist, ketamine, in humans: 


\section{MCQ answers \\ $1 d \quad 2$ e $\quad 3$ b $\quad 4$ e $\quad 5 c$}

psychotomimetic, perceptual, cognitive, and neuroendocrine responses. Archives of General Psychiatry, 51: 199-214.

Lai R, Katalinic N, Glue P, et al (2014) Pilot dose-response trial of i.v ketamine in treatment-resistant depression. World Journal of Biological Psychiatry, 15: 579-84

Lapidus KA, Levitch CF, Perez AM, et al (2014) A randomized controlled trial of intranasal ketamine in major depressive disorder. Biological Psychiatry, 76: 970-6.

Lee KH, Yeh YC, Yang PC, et al (2012) Individual and peer factors associated with ketamine use among adolescents in Taiwan. European Journal of Child and Adolescent Psychiatry, 21: 553-8.

Lee EE, Della Selva MP, Liu A, et al (2015) Ketamine as a novel treatment for major depressive disorder and bipolar depression: a systematic review and quantitative meta-analysis. General Hospital Psychiatry, 37: 178-84.

Li JH, Vicknasingam B, Cheung YW, et al (2011a) To use or not to use: an update on licit and illicit ketamine use. Substance Abuse and Rehabilitation, 16: 11-20.

Li N, Liu RJ, Dwyer JM, et al (2011b) Glutamate N-methyl-D-aspartate receptor antagonists rapidly reverse behavioral and synaptic deficits caused by chronic stress exposure. Biological Psychiatry, 69: 754-61.

Liao Y, Tang J, Corlett PR, et al (2011) Reduced dorsal prefrontal gray matter after chronic ketamine use. Biological Psychiatry, 69: 42-8.

Liu RJ, Lee FS, Li XY, et al (2011) Brain-derived neurotrophic factor Val66Met allele impairs basal and ketamine-stimulated synaptogenesis in prefrontal cortex. Biological Psychiatry, 71: 996-1005.

Lo JN, Cumming JF (1975) Interaction between sedative premedicants and ketamine in man in isolated perfused rat livers. Anesthesiology, 43: $307-12$

Lua AC, Lin HR, Tseng YT, et al (2003) Profiles of urine samples from participants at rave party in Taiwan: prevalence of ketamine and MDMA abuse. Forensic Science International, 136: 47-51.

Malhotra AK, Pinals DA, Adler CM, et al (1997) Ketamine-induced exacerbation of psychotic symptoms and cognitive impairment in neuroleptic-free schizophrenics. Neuropsychopharmacology, 17: 141-50.

Marshall E (1999) NIMH to screen studies for science and human risks. Science, 283: 464-5.

Mathew SJ, Murrough JW, aan het Rot M, et al (2010) Riluzole for relapse prevention following intravenous ketamine in treatment-resistant depression: a pilot randomized, placebo-controlled continuation trial. International Journal of Neuropsychopharmacology, 13: 71-82.

McCambridge J, Winstock A, Hunt N, et al (2007) 5-Year trends in use of hallucinogens and other adjunct drugs among UK dance drug users. European Addiction Research, 13: 57-64.

McKie R (2014) Health experts attack ketamine plan to tackle depression. The Guardian, 22 June.

Moghaddam B, Adams B, Verma A, et al (1997) Activation of glutamatergic neurotransmission by ketamine: a novel step in the pathway from NMDA receptor blockade to dopaminergic and cognitive disruptions associated with the prefrontal cortex. Journal of Neuroscience, 17: 2921-7.

Monteggia LM, Zarate C Jr (2015) Antidepressant actions of ketamine: from molecular mechanisms to clinical practice. Current Opinion in Neurobiology, 30: 139-43.

Morgan CJ, Muetzelfeldt L, Curran HV (2010) Consequences of chronic ketamine self-administration upon neurocognitive function and psychological wellbeing: a 1-year longitudinal study. Addiction, 105: 121-33

Morgan CJ, Curran HV, Independent Scientist Committee on Drugs (2012) Ketamine use: a review. Addiction, 107: 27-38.

Morgan CJ, Dodds CM, Furby H, et al (2014) Long-term heavy ketamine use is associated with spatial memory impairment and altered hippocampal activation. Frontiers in Psychiatry, 4: 149.

Murrough JW (2012) Ketamine as a novel antidepressant: from synapse to behaviour. Clinical Pharmacology and Therapeutics, 91: 303-9.
Murrough JW, Perez AM, Pillemer S, et al (2013a ) Rapid and longer-term antidepressant effects of repeated ketamine infusions in treatmentresistant major depression. Biological Psychiatry, 74: 250-6.

Murrough JW, losifescu DV, Chang LC, et al (2013b) Antidepressant efficacy of ketamine in treatment-resistant major depression: a twosite randomized controlled trial. American Journal of Psychiatry, 170: 1134-42.

Narendran R, Frankle WG, Keefe R, et al (2005) Altered prefrontal dopaminergic function in chronic recreational ketamine users. American Journal of Psychiatry, 162: 2352-9.

Naughton M, Clarke G, O'Leary OF, et al (2014) A review of ketamine in affective disorders: current evidence of clinical efficacy, limitations of use and pre-clinical evidence on proposed mechanisms of action. Journal of Affective Disorders, 156: 24-35.

Newport DJ, Carpenter LL, McDonald WM, et al (2015) Ketamine and other NMDA antagonists: early clinical trials and possible mechanisms in depression. American Journal of Psychiatry, 172: 950-66.

Nishitani N, Nagayasu K, Asaoka N, et al (2014) Raphe AMPA receptors and nicotinic acetylcholine receptors mediate ketamine-induced serotonin release in the rat prefrontal cortex. International Journal of Neuropsychopharmacology, 17: 1321-6

Noppers IM, Niesters M, Aarts LP, et al (2011) Drug-induced liver injury following a repeated course of ketamine treatment for chronic pain in CRPS type 1 patients: a report of 3 cases. Pain, 152: 2173.

Nunes EV, Deliyannides D, Donovan S, et al (1996) The management of treatment resistance in depressed patients with substance use disorders. Psychiatric Clinics of North America, 19: 311-27.

Olney JW, Labruyere J, Wang G, et al (1991) NMDA antagonist neurotoxicity: mechanism and prevention. Science, 254: 1515-8.

Papakostas Gl, Homberger CH, Fava M (2008) A meta-analysis of clinical trials comparing mirtazapine with selective serotonin reuptake inhibitors for the treatment of major depressive disorder. Journal of Psychopharmacology, 22: 843-8.

Pappachan JM, Raj B, Thomas S, et al (2014) Multiorgan dysfunction related to chronic ketamine abuse. Proceedings (Baylor University Medical Centre), 27: 223-5.

Quevedo J, Comim CM, Gavioli EC (2009) Ketamine induces rapid onset of antidepressant action: neurophysiological biomarkers as predictors of effect. Biomarker Medicine, 3: 5-8.

Rasmussen KG (2016) Has psychiatry tamed the "ketamine tiger"? Considerations on its use for depression and anxiety. Progress in Neuropsychopharmacology, 64: 218-24.

Robson MJ, Elliott M, Seminerio MJ, et al (2012) Evaluation of sigma (sigma) receptors in the antidepressant-like effects of ketamine in vitro and in vivo. European Neuropsychopharmacology, 22: 308-17.

Sackeim HA (2001) The definition and meaning of treatment-resistant depression. Journal of Clinical Psychiatry, 62 (suppl 16): 10-7.

Salvadore G, Singh JB (2013) Ketamine as a fast acting antidepressant: current knowledge and open questions. CNS Neuroscience and Therapeutics, 19: 428-36.

Sanacora G, Zarate CA, Krystal JH, et al (2008) Targetting the glumatergic system to develop novel, improved therapeutics for mood disorders. Nature Reviews Drug Discovery, 7: 426-37.

Sanacora G, Schatzberg AF (2015) Ketamine: promising path or false prophecy in the development of novel therapeutics for mood disorders? Neuropsychopharmacology, 40: 259-67.

Schatzberg AF (2014) A word to the wise about ketamine. American Journal of Psychiatry, 171: 262-4

Shram MJ, Sellers EM, Romach MK (2011) Oral ketamine as a positive control in human abuse potential studies. Drug and Alcohol Dependence, 114: 185-93.

Siddique H (2014) Ketamine may help treat depression, UK study finds. The Guardian, 13 April. 
Sinner B, Graf BM (2008) Ketamine. In Modern Anesthetics (eds J Schuttler, H Schwilden): 313-33 (Handbook of Experimental Pharmacology, vol 182). Springer.

Sisti D, Segal AG, Thase ME (2014) Proceed with caution: off-label ketamine treatment for major depressive disorder. Current Psychiatry Reports, 16: 527.

Smith K, Flatley J (eds) (2011) Drug Misuse Declared: Findings from the 2010/11 British Crime Survey. England and Wales (HOSB: 12/11). Home Office.

Sokero TP, Melartin TK, Rytsala HJ, et al (2003) Suicidal ideation and attempts among psychiatric patients with major depressive disorder. Journal of Clinical Psychiatry, 64: 1094-100.

Sonawalla SB, Rosenbaum JF (2002) Placebo response in depression. Dialogues in Clinical Neuroscience, 4: 105-13.

Stahl SM (2014) Stahl's Essential Psychopharmacology Prescriber's Guide Antidepressants (5th edn). Cambridge University Press.

Stone JM, Dietrich C, Edden R, et al (2012) Ketamine effects on brain GABA and glutamate levels with 1H-MRS: relationship to ketamineinduced psychopathology. Molecular Psychiatry, 17: 664-5.

Substance Abuse and Mental Health Services Administration (2003) Emergency Department Trends from the Drug Abuse Warning Network: Final Estimates 1995-2002 (Drug Abuse Warning Network Series: D-24). US Department of Health and Human Services.

Szymkowicz SM, Finnegan N, Dale RM (2014) Failed response to repeat intravenous ketamine infusions in geriatric patients with major depressive disorder. Journal of Clinical Psychopharmacology, 34: 285-6.

Tan S, Lam WF, Wai MS, et al (2012) Chronic ketamine administration modulates midbrain dopamine system in mice. PLOS ONE, 7: e43947.

Tang WK, Morgan CJ, Lau GC, et al (2015) Psychiatric morbidity in ketamine users attending counselling and youth outreach services. Substance Abuse, 36: 67-74.

Taylor MJ, Freemantle N, Geddes JR, et al (2006) Early onset of selective serotonin reuptake inhibitor antidepressant action: systematic review and meta-analysis. Archives of General Psychiatry, 63: 1217-23.

Taylor D, Paton C, Kapur S (2015) The Maudsley Prescribing Guidelines in Psychiatry (12th edn). Wiley-Blackwell.
Thakurta RG, Ray P, Kanii D, et al (2012) Rapid antidepressant response with ketamine: is it the solution to resistant depression? Indian Journal of Psychological Medicine, 34: 56-60.

Torre RD (2010) Commentary on Morgan et al (2010) Ketamine abuse: first medical evidence of harms we should confront. Addiction, 105: 134-5.

Toyama Y, Shimizu H, Suzuki Y, et al (2006) Genotoxic effects of N-nitrosoketamine and ketamine as assessed by in vitro micronucleus test in Chinese hamster lung fibroblast cell line. Environmental Health and Preventive Medicine 11: 120-7.

Trujillo KA, Smith ML, Sullivan B, et al (2011) The neurobehavioral pharmacology of ketamine: implications for drug abuse, addiction, and psychiatric disorders. Laboratory Animal Research Journal, 52: 366-78.

Wise RA (1988) Psychomotor stimulant properties of addictive drugs. Annals of New York Academy of Science, 537: 228-34.

Xu K, Lipsky RH (2015) Repeated ketamine administration: alters $\mathrm{N}$-methyl-D-aspartic acid receptor subunit gene expression: implication of genetic vulnerability for ketamine abuse and ketamine psychosis in humans. Experimental Biology and Medicine, 240: 145-55.

Yang C, Hashimoto K (2014) Rapid antidepressant effects and abuse liability of ketamine. Psychopharmacology, 231: 2041-2.

Yang C, Shirayama Y, Zhang JC, et al (2015) R-ketamine: a rapid-onset and sustained antidepressant without psychotomimetic side effects. Translational Psychiatry, 1(5): e632.

Zarate CA Jr, Singh JB, Carlson PJ, et al (2006) A randomized trial of an $\mathrm{N}$-methyl-D-aspartate antagonist in treatment-resistant major depression. Archives of General Psychiatry, 63: 856-64.

Zarate CA Jr, Brutsche NE, Ibrahim L, et al (2012) Replication of ketamine's antidepressant efficacy in bipolar depression: a randomized controlled add-on trial. Biological Psychiatry, 71: 939-46.

Zhang JC, Li SX, Hashimoto K (2014) R(-)-ketamine shows greater potency and longer lasting antidepressant effects than $\mathrm{S}(+)$-ketamine. Pharmacology Biochemistry and Behavior, 116: 137-41.

Zhang MW, Ho RC (2015) Ketamine's potential as a rapid antidepressant was overplayed. BMJ, 351: h4467.
MCQs

Select the single best option for each question stem

1 In the 1990s, US researchers conducted a study that used ketamine to induce psychosis. Which of the following statements is false?

a The researchers recruited patients with schizophrenia

b The study was stopped owing to ethical concerns

c This was a single-centre study

d This study yielded important findings that changed antipsychotic prescription practice when treating schizophrenia

e This study aimed to understand the efficacy of drugs for schizophrenia.

\section{Which of the following binding sites is the} site of action for ketamine?

a Cannabinoid binding site of the NMDA receptors

b Dopamine binding site of the NMDA receptors c Gamma-aminobutyric acid (GABA) binding site of the NMDA receptors

d Glutamate binding site of the NMDA receptors

e Phencyclidine (PCP) binding site of the NMDA receptors.

3 Which of the following side-effects is not common after a single ketamine infusion?

a Dissociation

b Incontinence

c Increase in skeletal muscle tone

d Increase in blood pressure

e Psychosis.

4 Which of the following has not been shown by trials of ketamine involving patients with depression?

a Patients with a small hippocampus are more likely to respond to ketamine infusion

b Patients with homozygous met/met alleles of the $B D N F$ gene are more likely to respond to ketamine infusion c There is a wide variation in response rate

d A single infusion of ketamine at $0.5 \mathrm{mg} / \mathrm{kg}$ can reduce severity of depression

e A single infusion of ketamine at $0.5 \mathrm{mg} / \mathrm{kg}$ often leads to permanent cure of depression.

5 Which of the following countries does not have legislation to control and restrict the use of ketamine?

a Canada

b Denmark

c The Netherlands

d The UK

e The USA. 